\title{
Jogos digitais na educação a distância: percepção dos adultos sobre o lúdico e a aprendizagem
}

\author{
Bruna Santana Anastácio \\ Daniela Karine Ramos
}

\section{Resumo}

Este artigo tem como objetivo caracterizar o modo como os adultos interagem com os jogos digitais em contextos educacionais, identificando suas percepções sobre o jogo e como os aspectos lúdicos são percebidos no processo de aprendizagem. Para tanto, fez-se uma pesquisa de abordagem qualitativa, utilizando a observação livre, a realização de entrevistas semiestruturadas e a aplicação de um questionário, para analisar as relações entre os alunos de um curso de extensão a distância e o jogo "Saga dos Conselhos", o qual se inseriu como atividade prevista no planejamento. Os resultados indicaram que há uma diferença geracional frente ao uso das tecnologias, identificando-se em alguns momentos familiaridade e em outros, novidade para os cursistas. Ainda que aplicado em contexto educacional voltado para o adulto, recorrentemente tem-se uma valorização do uso dos jogos digitais para as crianças. Ao mesmo tempo em que os adultos ressaltam as questões lúdicas encontradas no jogo e reconhecem que a aprendizagem tornou-se mais motivadora e interessante.

Palavras-chave: Ensino Superior. Jogos. Tecnologias na educação.

\section{Digital games in distance education: adults' perception of ludic and learning}

\section{Abstract}

This article aims to analyze the way adults interact with digital games in educational contexts, identifying their perceptions about the game and how the ludic aspects are perceived in the learning process. For that, a qualitative research was carried out, using free observation, semi-structured interviews and the application of a questionnaire, to analyze the relations between the students of a course of distance extension and the 
game "Saga dos Conselhos", which was inserted as an activity planned. The results indicated that there is a generational difference in the use of technologies, in some cases the familiarity is identified and in others the game appears as novelty for the students. Although applied in an adult-oriented educational context, there is a recurrent appreciation of the use of digital games for children. At the same time as adults highlight the playful issues encountered in the game and recognize that learning has become more motivating and interesting.

Keywords: Higher education. Games. Technologies in education.

\section{Juegos digitales en la educación a distancia: percepción de los adultos sobre el lúdico y el aprendizaje}

\section{Resumen}

Este artículo tiene como objetivo analizar el modo como los adultos interactúan con los juegos digitales en contextos educativos, identificando sus percepciones sobre el juego y cómo los aspectos lúdicos son percibidos en el proceso de aprendizaje. Para ello, se realizó una investigación de abordaje cualitativo, utilizando la observación libre, la realización de entrevistas semiestructuradas y la aplicación de un cuestionario, para analizar las relaciones entre los alumnos de un curso de extensión a distancia y el juego "Saga dos Conselhos", en el cual se insertó como actividad prevista en la planificación. Los resultados indicaron que hay una diferencia generacional frente al uso de las tecnologías, en que se identifica familiaridad en algunos momentos y, en otros, como novedad para los cursistas. Aunque se aplica en un contexto educativo orientado hacia el adulto, recurrentemente se tiene una valorización del uso de los juegos digitales para los niños. Al mismo tiempo que los adultos resaltan las cuestiones lúdicas encontradas en el juego y reconocen que el aprendizaje se ha vuelto más motivador e interesante.

Palabras clave: Enseñanza superior. Juegos. Tecnologías en la educación.

\section{Introdução}

Inseridos no universo das tecnologias, a sociedade encontrase em constante adequação de saberes e práticas, inclusive perpassando o campo da educação. No contexto atual, as Tecnologias Digitais de Informação e da Comunicação (TDIC) estão inseridas em 
nossas tarefas cotidianas e em diferentes áreas de atuação, oferecendo novas formas de interpretação do mundo e trazendo novas perspectivas e desafios para a sociedade contemporânea. Diante disso, na perspectiva de Martín-Barbero (2014), a tecnologia desloca os saberes, modificando tanto o estatuto cognitivo como institucional das condições do saber, conduzindo a um forte apagamento das fronteiras entre razão e imaginação, saber e informação, natureza e artifício, arte e ciência, saber experto e experiência profana. Nesse viés, Lévy (1993) também contribui afirmando acerca da predominância de determinadas tecnologias - desenvolvidas para garantir ao homem a superação de obstáculos naturais e a sobrevivência com melhor qualidade de vida, em cada lugar e em cada época necessariamente encaminha as pessoas para novas aprendizagens, não restritas apenas para o domínio de determinados conteúdos ou competências específicas.

No campo da educação, o uso das tecnologias pode contribuir para os processos de aprendizagem, possibilitando meios para o acesso às informações, produção de conhecimento e alternativas de comunicação. Dessa forma, Barreto (2002) acredita na capacidade das tecnologias, de desencadear mudanças significativas no processo de ensino e aprendizagem, bem como, de minimizar a lacuna entre as práticas escolares e as demais práticas sociais de docentes e discentes.

Diante disso, este trabalho volta-se para a investigação do uso de jogos digitais em contextos educacionais direcionados ao público adulto, mais especificamente na educação a distância, tendo o objetivo de analisar o modo como os adultos interagem com os jogos digitais em contextos educacionais, identificando suas percepções sobre o jogo e como os aspectos lúdicos são percebidos no processo de aprendizagem. Para tanto, analisamos as relações entre os alunos do ensino superior e o jogo educacional "Saga dos Conselhos". A partir disso, algumas questões nortearam esta investigação como: Quais são as relações entre os adultos e os jogos? Será que conseguem se divertir jogando? O lúdico é um elemento 
importante para a aprendizagem? O jogo pode ser visto como uma potencialidade na educação?

\section{Relações entre jogos digitais e ensino superior: novas formas de aprendizagem}

As TDIC estão fortemente inseridas em diversos contextos de nosso cotidiano, perpassando inclusive o campo educacional, colaborando para transformações e desafios nos processos de ensino e aprendizagem, seja de crianças seja de adultos. Diante disso, as TDIC contribuem para essas transformações uma vez que modificam radicalmente os ambientes e contextos de aprendizagem, fazendo que espaços formais de educação como a escola e a universidade sejam repensadas e ressignificadas, proporcionando, assim, novas possibilidades e perspectivas para uma educação mais aberta, acessível e flexível (RABELLO; TAVARES, 2016).

Nessa perspectiva, lançamos nosso olhar à educação a distância a fim de compreender as suas relações e perspectivas sobre o uso das tecnologias. Moran (2000) destaca que a utilização de tecnologias digitais pode estimular os alunos a realizarem pesquisas e atividades desafiadoras, combinando tarefas integradas dentro e fora da sala de aula, ampliando, assim, os locais e contextos de aprendizagem.

Como possibilidade de uso das tecnologias na educação, temse o uso de jogos digitais com uma alternativa lúdica e motivadora. Nesse sentido, os jogos digitais podem ser definidos como uma atividade lúdica composta por uma série de ações e decisões, limitados por regras e pelo universo do game, resultando em uma condição final (SCHUYTEMA, 2008). Nessa perspectiva, Juul (2005) define os jogos digitais de maneira mais detalhada, como um sistema formal ancorado em regras, com resultados variáveis e quantificáveis, de diferentes resultados, que são atribuídos a diferentes valores, de um jogador exercer esforço a fim de influenciar o resultado, no qual o jogador sente-se emocionalmente ligado ao resultado e as consequências da atividade são opcionais e negociáveis. 
Os jogos digitais possuem características importantes que podem contribuir com os processos de ensino e aprendizagem. Entre as principais destacadas por Mc Gonigal (2012) temos: a) ter objetivos a alcançar, b) regras a cumprir, c) participação voluntária e d) feedbacks. Nessa perspectiva, os objetivos têm, sobretudo, a função de motivar o jogador e pautar a mensuração de ser desempenho (PRENSKY, 2012), as regras direcionam as ações do jogo e moldam o seu universo para os jogadores, além de criar situações interessantes com o objetivo de desafiar e se contrapor ao jogador (SCHUYTEMA, 2008). Outro aspecto, se refere ao fato de que a participação precisa ser voluntária e a presença de feedbacks oferece aos jogadores a possibilidade de reconhecer os seus erros e perceber que poderiam ter atuado de forma diferente dentro do jogo (GEE, 2008). Nesse sentido, Kiili (2005) reforça a importância para a aprendizagem ancorada no uso dos jogos digitais do fornecimento de feedback imediato ao jogador, a definição de metas claras e a proposição de desafios compatíveis com o nível do jogador (KIILI, 2005).

Além das características destacadas, o exercício de jogar envolve o recrutamento de diferentes áreas do cérebro, pois os jogos digitais apresentam-se como uma atividade (ou processo), em que os jogadores tomam decisões ativamente, focando objetivos e dentro de um contexto de regras que limitam e estruturam essa atividade (SALEN; ZIMMERMAN, 2012). De forma mais objetiva, Ramos (2008) salienta que, ao jogar, lidamos com várias metas, tarefas e variáveis simultaneamente e precisamos trabalhar de modo intencional e organizado.

Os jogos digitais utilizados em contextos educacionais envolvem não só os conteúdos curriculares, mas também exercitam o uso da lógica, da memória, da capacidade de resolução de problemas, a atenção, envolve a exploração e a descoberta e melhoram a motivação dos alunos em relação aos assuntos abordados, resultando em uma aprendizagem mais efetiva (ANNETTA, 2008).

O jogo, ainda, é fortemente reconhecido por se constituir como atividade lúdica, o que pode ser associado com impactos 
a respeito da motivação e interesse dos alunos (SCHUYTEMA, 2008). Segundo Anastácio (2016), os jogos digitais possuem um impacto sobre a aprendizagem, tornando-a mais divertida e lúdica.

As características do jogo, especialmente relacionadas à estrutura organizada e lúdica, podem oferecer contribuições ao desenvolvimento e aprendizagem dos alunos no contexto educacional (RAMOS, 2014). De forma mais geral, precisamos colocar o lúdico a serviço da aprendizagem, onde o jogador participe de uma experiência lúdica na qual o envolva acerca da atividade desenvolvida dentro do jogo (SANTAELLA, 2013).

Diante desse contexto, é preciso compreender o lúdico e o seu potencial para a aprendizagem, seja de crianças seja de adultos. Nessa perspectiva, de acordo com Luckesi (2005), entendemos a atividade lúdica como uma oportunidade de experiência plena, sendo importante estar atento para o "olhar", na dimensão do eu, do interno, além de defender o brincar, o jogar e o agir ludicamente, enquanto algo que exige uma entrega total do ser humano, corpo e mente. De forma complementar, Pereira (2005) ressalta que as atividades lúdicas, que têm na busca da alegria e do prazer sua grande alimentadora, se caracterizam como atividades não impostas, experienciadas individualmente ou compartilhadas, tendo como finalidade a vivência do momento presente.

Ao destacar as relações dos adultos com os jogos e com a ideia de divertimento, Ferreira et al. (2004) fazem um contraponto, salientando que a ideia de lúdico para os adultos é mais severa, pois não lhes permite vivenciar a ludicidade plena. Talvez isso ocorra porque se considera a fase adulta de extrema importância à produtividade e, também, por ser o jogar e o brincar, visto pela sociedade capitalista como uma perda de tempo.

No contexto da aprendizagem, o potencial lúdico que os jogos digitais reforçam são sentidos por Prensky (2012), quando afirma que a aprendizagem ancorada em jogos digitais trata precisamente de diversão, do envolvimento e da junção da aprendizagem séria ao entretenimento interativo em um meio recém-surgido e extremamente empolgante. 
Nesse contexto, pesquisas têm apontado para as contribuições do uso dos jogos digitais para a aprendizagem de adultos. Hainey et al. (2013), em sua pesquisa realizada visando sistematizar evidências que apoiem o uso de jogos na educação, também têm como público adultos, incluindo alunos da educação a distância. Este estudo foi feito com 887 alunos de 13 instituições de ensino superior na Escócia e na Holanda para examinar as características dos alunos, as preferências em relação aos jogos, hábitos de jogo e suas percepções sobre o uso de jogos na educação. Os resultados revelaram que um grande número de participantes acreditava que os jogos de computador poderiam ser usados na educação de adultos, mas encontraram diferenças entre alunos de cursos presenciais e a distância, os alunos da educação presencial de ambos os países classificaram todas as motivações para jogar jogos digitais como significativamente mais importantes do que estudantes de educação a distância (HAINEY et al., 2013).

Outro estudo desenvolvido por Fu e Yu (2006) realizado com 120 estudantes de graduação, para explorar o envolvimento do aprendiz ao se utilizar jogos em curso a distância, destaca características dos jogos que podem ser associadas à aprendizagem. As conclusões do estudo destacam o desafio e a recompensa como motivação positiva para incentivar o envolvimento do aluno.

Diante disso, passamos a descrever e caracterizar a pesquisa desenvolvida, incluindo a breve descrição do jogo utilizado e a caracterização dos participantes, para analisar os resultados obtidos e destacar algumas evidências relacionadas ao uso dos jogos digitais em contextos educacionais formais.

\section{Metodologia}

A pesquisa realizada caracteriza-se por ter uma abordagem qualitativa, pois trabalha com o universo de significados, motivos, aspirações, crenças, valores e atitudes, procurando estabelecer um espaço mais profundo das relações, dos processos e dos fenômenos que não podem ser reduzidos à operacionalização de variáveis (MINAYO, 1994). 
O contexto da pesquisa foi a oferta do Curso de Extensão a Distância de Formação Continuada em Conselhos Escolares, pela Universidade Federal de Santa Catarina (UFSC). Esse curso se refere a uma das ações do Programa Nacional de Fortalecimento dos Conselhos Escolares da Secretaria de Educação Básica do Ministério da Educação. Nesse contexto, analisou-se o uso do jogo digital "Saga dos Conselhos", desenvolvido pela UFSC, com o objetivo de reforçar e revisar os conteúdos estudados ao longo do curso, integrandose ao seu currículo como uma atividade proposta aos cursistas.

O jogo digital "Saga dos Conselhos" ao longo da trajetória vai combinando a proposição de cinco tipos de minigames distintos que envolvem desafios como responder perguntas, completar frases, organizar mapas conceituais e classificar afirmações em categorias associadas aos temas que rodeiam o universo de um conselho escolar. A contextualização do jogo, bem como, o cenário, narrativa e personagens procura promover uma aproximação com o universo dos adultos, nesse caso jogadores.

Figura 1 - Tela inicial do jogo digital "Saga dos Conselhos"

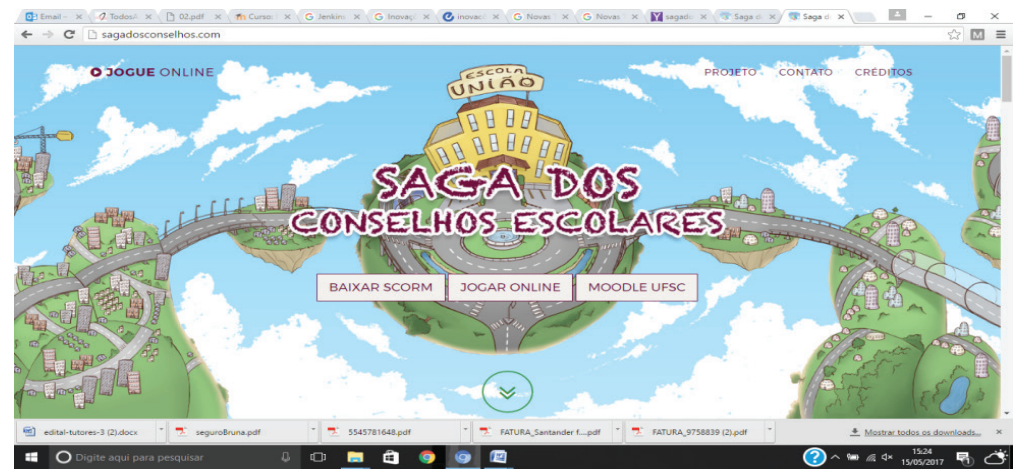

Fonte: Saga dos Conselhos (2015)

No jogo "Saga dos Conselhos", o jogador é apresentado ao João, um aluno da escola União e um dos participantes do Conselho Escolar. Ao longo da narrativa do jogo, João responde aos minigames, avança nos níveis e conquista outros personagens para 
compor conselho escolar como: professor, secretária, mãe do aluno, entre outros.

Figura 2 - Tela do jogo digital "Saga dos Conselhos"

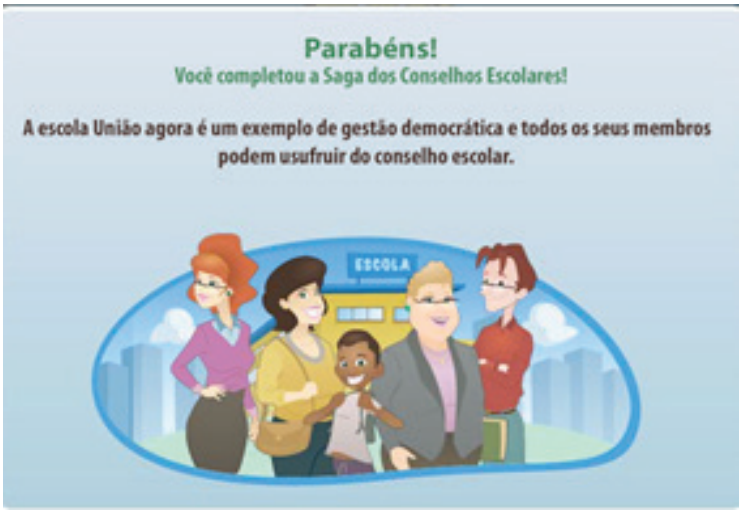

Fonte: Saga dos Conselhos (2015)

O contexto da pesquisa contabilizava 122 cursistas que participaram de dois momentos distintos da coleta. Um momento da coleta de dados foi realizado no encontro presencial do Curso de Extensão a Distância de Formação Continuada em Conselhos Escolares, ocasião em que os cursistas estavam presentes na universidade. A amostra da pesquisa foi composta por 19 cursistas, sendo que destes 17 deles eram do sexo feminino e somente 2 do sexo masculino, que já haviam tido contato com o jogo "Saga dos Conselhos". Outra coleta foi realizada a distância e teve a participação de 54 cursistas. A faixa etária dos cursistas é entre 21 e 60 anos, mas a maioria deles possui entre 41 e 50 anos.

Em um primeiro momento, os cursistas foram organizados em dois grupos e convidados a jogar o "Saga dos Conselhos". Esse momento foi filmado e serviu como objeto das observações livres (MINAYO, 2007), visando apreender o modo como os cursistas interagiam com o jogo, se expressavam por comportamentos ou oralmente. 
Após esse momento, foram realizadas entrevistas individuais, oportunizando aos participantes a possibilidade de dialogar, discutir e avaliar suas experiências com o jogo digital "Saga dos Conselhos", com base em um roteiro semiestruturado.

Para análise, as entrevistas foram gravadas em áudio, transcritas e submetidas a uma leitura flutuante para definição das categorias de análise para a organização dos dados. Após esse procedimento, foram analisadas por meio da Análise de Conteúdo proposta por Bardin (2007) que, de forma geral, analisa os conteúdos das mensagens por intermédio de um conjunto de técnicas de análise das comunicações.

Além das entrevistas, utilizou-se também um questionário on-line com questões pontuais relacionadas ao perfil dos jogadores. O questionário on-line foi respondido à distância por meio da própria plataforma onde o curso era ofertado. E sua análise pautou-se na tabulação dos dados e na estatística descritiva.

\section{Resultados e discussão}

Diante da experiência com o jogo "Saga dos Conselhos" os alunos do ensino superior, que são todos adultos, puderam perceber as contribuições que o jogo ofereceu para a sua aprendizagem, destacando as questões lúdicas envolvidas, como uma atividade mais interessante e motivadora para a aprendizagem.

No momento de observação, as pesquisadoras conseguiram identificar certa familiaridade e dificuldade presentes no grupo de alunos, identificadas principalmente pelos pedidos de ajuda quanto ao uso da tecnologia e pelo modo como expressavam seu entendimento sobre as mecânicas e desafios do jogo digital. Muitos cursistas solicitavam auxílio aos pesquisadores ou colegas para iniciar o jogo, saber o que era para fazer no jogo ou onde clicar, por exemplo.

Essas observações foram reforçadas nas entrevistas, nas quais muitos adultos reconheceram não ter contato anterior com jogos digitais, outros jogavam ocasionalmente como um passatempo, entretanto alguns cursistas afirmaram que costumavam 
jogar. Esse perfil diferenciado pode ser analisado com base em relatos como: "Não! Nada... nem no celular, só canastra! Na cartinha mesmo!" (Entrevistado 5) e também ouvimos sobre a familiaridade com os jogos e seus aspectos positivos: "Então, eu jogo bastante tá? Eu acho que sim, que a gente aprende muito porque assim coordenação motora, criatividade sabe, pra criança também" (Entrevistado 2).

Diante dos relatos registrados nas entrevistas, percebemos que os adultos relacionam fortemente o uso dos jogos com as crianças, identificando o jogo digital como algo distante do universo dos adultos. Esse fato pode ser ilustrado por meio da fala: "É muito importante assim, principalmente assim, pra criança né. Para as crianças tudo que tu oferecer de jogo né, vai levar a um raciocínio, a uma busca de resultado como é... a rapidez na criança né! As crianças são bastante curiosas!” (Entrevistado 4). Nesse sentido, Prensky (2012) colabora com essa dicotomia criança/adulto e jogo, ressaltando que a aprendizagem ancorada em jogos digitais para crianças funciona bem e questiona se os adultos querem aprender com os jogos. Segundo ele, os adultos amadurecem e se tornam mais sérios, porém a diversão dos jogos está presente, mesmo na idade adulta (PRENSKY, 2012).

Nesse contexto, utilizamos os dados do questionário com o objetivo de conhecer o público-alvo do curso, os adultos, bem como, suas experiências com o uso de jogos para fins educacionais. Com a utilização dos questionários, percebemos as relações dos adultos quando o assunto é jogo e obtivemos os seguintes resultados: dos 54 respondentes do questionário - 25 responderam que não jogavam, 7 responderam que jogavam e 22 adultos optaram pela opção “às vezes”, como ilustrado a seguir: 
Gráfico 1 - Experiência prévia dos adultos participantes com jogos digitais

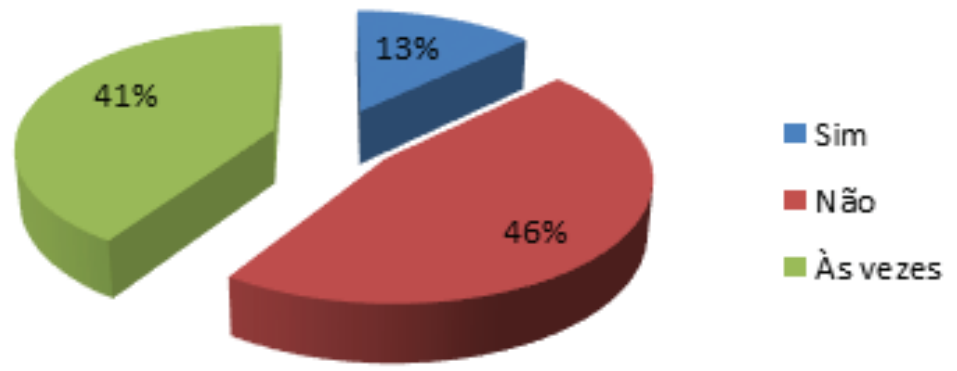

Fonte: Elaboração das autoras

O Gráfico 1 demonstra que a maior parte dos cursistas, o que corresponde a 46\%, não possui o hábito de jogar. Em alguns momentos das entrevistas, as opções de jogar ou não jogar são explicadas pelos entrevistados como: "Então, eu jogo bastante tá?" (Entrevistado 2), "Eu costumo jogar, jogo no computador, jogo no celular e isso é bom!" (Entrevistado 7) ou "Não! Nada... Nem no celular, só canastra! Na cartinha mesmo" (Entrevistado 5), "Não, primeira vez. Isso aí, primeira vez!" (Entrevistado 4) ou ainda demonstram convicção ao explicar o motivo pelo qual não jogam: "Nós somos uma era menos tecnológica, pra nós não é tão atrativo, mas pra quem está vindo, né, os mais novos, eu já estou velha, mas os mais novos isso se torna atrativo porque eles estão habituados a jogar" (Entrevistado 5).

Esses resultados evidenciam que temos uma diversidade de experiências com jogos digitais que incluem parte dos cursistas que não interagem com jogos digitais. A partir disso, observa-se que algumas diferenças no perfil dos cursistas, como serem jogadores ou não, tem pouca influencia sobre as experiências de aprendizagem baseadas no uso dos jogos, reforçando que os jogos digitais em contextos educacionais podem atender a diferentes objetivos de aprendizagem, ser aplicados em quase todos os campos e com cursistas de todas as idades (HOUDA et al., 2012). 
Nas percepções de alguns cursistas, evidencia-se a crença de que os jogos são para crianças e adolescentes, reconhecendo as potencialidades das tecnologias somente para esse público e mantendo certo distanciamento quanto às tecnologias, aspecto que pode se evidência na fala: "Eu acho que principalmente o adolescente é bastante visual, eles adoram novas tecnologias, não vivem sem o celular, eu uso e tenho e é uma ferramenta mas pra mim o celular não é fundamental, eu tenho outros interesses que eu prefiro, eu uso e-mail, ambiente virtual eu conheço mas não é o que mais me atrai" (Entrevistado 14). Nesse viés, mesmo com esse distanciamento sentido entre adultos e tecnologias, estes fazem uso de jogos como estímulo à aprendizagem das crianças, sejam eles, alunos, os filhos ou como uma forma de diversão ou passatempo com a família. Esse aspecto reforça a ideia descrita por Ferreira et al. (2004) de que o adulto tem mais dificuldade para vivenciar o divertimento e o lúdico.

Quando perguntados sobre o ato de jogar dos adultos, o fato de utilizarem os jogos para as crianças aparece ilustrado por meio da fala: "Só no computador de casa, jogar mais jogar com as crianças em casa, jogar aquele soletrando, aquele jogo do Silvio Santos que elas fazem" (Entrevistado 15) ou de outra forma, como uma contribuição para a aprendizagem: "Minha filha gosta muito assim (jogos digitais) e ai eu queria que ela se alfabetizasse e ai ela meia preguiçosa e ai eu falava vamos jogar com a mãe e ai a gente jogava, ela aprendia a ler e tinha coisas que ela gostava e ai foi uma forma que eu achei de ela evoluir né" (Entrevistado 2). Esses aspectos reforçam a ideia de que o uso dos jogos digitais na educação dessa nova geração tende a gerar um maior envolvimento e experiências de aprendizagem mais motivadoras, proporcionando curiosidade e diversão (ANNETT'TA, 2008).

Essas características levam muitos adultos a associarem o uso das tecnologias com o universo da criança: "Justamente, já faz parte (do universo da criança)! Tecnologia pra criança é uma coisa que facilmente né. O único problema que eu vejo é a gente ter que saber impor os limites né" (Entrevistado 8). Diante disso, per- 
cebemos que os adultos não relacionam a ideia do lúdico ao seu universo, talvez isso ocorra porque se considera que a fase adulta é de extrema importância à produtividade e também porque o jogar e o brincar são vistos pela sociedade capitalista como uma perda de tempo (FERREIRA et al., 2004).

Apesar disso, nesta pesquisa, as questões lúdicas envolvidas para a aprendizagem foram sentidas pelos adultos como positivas, como ilustrado a seguir: "Acho que o jogo faz a gente refletir sobre uma determinada realidade. Esse jogo específico ele me faz relembrar conceitos que eu já tinha. Eu já participei muito de conselhos escolares lá na escola e tem certos conceitos que ficam perdidos, meio esquecidos com o tempo. O jogo tem essa coisa lúdica de estar retomando esse conhecimento" (Entrevistado 18) ou ainda relacionado à aprendizagem: "Já tive experiência com jogos em jogos de matemática e vejo que eles aprendem mais, eles se divertem mais e parece que aprendem mais, como nós aqui, eu acho uma boa maneira de aprendizado" (Entrevistado 19). As contribuições dos usos dos jogos à aprendizagem na educação a distância também são evidenciadas na pesquisa de Annetta (2008), que ao descrever uma experiência de uso de um jogo digital na educação a distância, reforça o seu potencial para aprendizagem, indicando que esse recurso pode ser uma alternativa para cursos pautados em explicações escritas, em vídeos ou por recursos de comunicação síncrona.

Dessa forma, e com base nas análises das entrevistas realizadas em nossa pesquisa, percebe-se que os adultos valorizam a utilização do jogo para fins educacionais e associam o seu uso ao divertimento, como bem expressa o entrevistado 19 ao relatar sua experiência de uso dos jogos para o ensino de matemática: “Já tive experiência com jogos em jogos de matemática e vejo que eles aprendem mais, ele se divertem mais e parece que aprendem mais, como nós aqui, eu acho uma boa maneira de aprendizado".

A possibilidade de termos uma aprendizagem de conteúdos associada à diversão constitui-se como uma das contribuições do uso dos jogos digitais na educação. Esse aspecto é valorizado em pesqui- 
sas como de Minović et al. (2015), que propõem uma ferramenta para acompanhar a aprendizagem dos alunos na interação com um jogo, por reconhecer que o uso de jogos na educação a distância possibilita que o cursista se divirta e aprenda ao mesmo tempo.

Diante disso, quando inseridos em contextos educacionais, os jogos precisam ter objetivos definidos, promovendo o desenvolvimento de estratégias e habilidades importantes para ampliar a capacidade cognitiva e intelectual dos alunos, quando utilizados para fins educacionais (SAVI; ULBRICHT, 2008). O uso e o desenvolvimento de jogos digitais em situações de ensino ou treinamento têm sido conhecidos como jogos sérios, também conhecidos como serious games (ANNETA, 2008) ou jogos educacionais que abordam conteúdos e objetivam a aprendizagem dos alunos (DEMPSEY et al., 1996; GRAMIGNA, 2007) em contextos formais de educação.

Além disso, Moratori (2003) reforça que para que o jogo seja útil no processo educacional, ele deve promover situações interessantes e desafiadoras para a resolução de problemas, permitindo aos aprendizes uma autoavaliação quanto aos seus desempenhos, além de fazer que todos os jogadores participem ativamente de todas as etapas.

Nesse contexto do uso de jogos digitais para fins educacionais para o público adulto, destacamos o potencial de aprendizagem que eles possuem, bem como, a associação de uma aprendizagem mais motivadora e lúdica. Diante disso, Grubel e Bez (2006) colaboram ressaltando que os jogos digitais podem facilitar o processo de ensino-aprendizagem e ainda proporcionarem experiências prazerosas, interessantes e desafiantes, transformando-os em uma estratégia de ensino para os educadores além de ser um rico instrumento para a construção do conhecimento. De modo geral, os jogos digitais potencializam a aprendizagem, permitindo a elaboração de reflexões críticas que vão delineando no próprio ato de jogar acrescentados ao divertimento, um dos traços fundamentais do ato de jogar, que resiste às interpretações lógicas e racionalistas (SANTAELLA, 2012). 
De modo geral, reforçamos que a aprendizagem ancorada em jogos tem sido reconhecida em contextos educacionais, pois se constitui em uma abordagem potencialmente efetiva para o ensino e a aprendizagem, entretanto ainda temos poucas evidências em contextos mais amplos de uso de jogos digitais na educação (HAINEY et al., 2013). Esse fato evidencia que, ao mesmo tempo em que temos o uso massivo dos jogos digitais no cotidiano para o entretenimento, ainda precisamos avançar na melhor compreensão de seus potenciais para o uso na educação.

\section{Considerações finais}

Os resultados indicam que o uso do jogo digital "Saga dos Conselhos" com o público adulto promoveu a aprendizagem dos cursistas no curso, reforçando que os jogos digitais podem ser utilizados para fins educacionais, seja para crianças seja para adultos.

Outro aspecto que ganhou destaque na percepção dos cursistas se refere à diferença geracional entre adultos e crianças que está muito presente nas falas dos entrevistados. Ao mesmo tempo em que reconhecem o potencial dos jogos digitais para a aprendizagem aliado às questões lúdicas, percebemos certo distanciamento dos adultos frente ao uso dos jogos digitais para a aprendizagem, valorizando o seu uso para o público infantil. Porém, eles ressaltam as questões lúdicas abordando uma retomada dos conhecimentos e tornando a aprendizagem mais divertida.

Dessa forma, ressaltamos a importância da utilização de jogos digitais para a aprendizagem, seja com adultos seja com crianças, pois os jogos favorecem a aprendizagem mais interessante e motivadora. Ao mesmo tempo, o uso dos jogos na educação a distância pode se revelar como uma alternativa à diversificação dos recursos didáticos e maior engajamento dos cursistas em relação à sua aprendizagem. 


\section{Referências}

ANASTÁCIO, Bruna Santana. Contextos lúdicos de aprendizagem: uma aproximação entre os jogos eletrônicos e a educação a distância. Dissertação de Mestrado. Universidade Federal de Santa Catarina. Florianópolis, 2016.

ANNETTA, Leonard A. Video Games in Education: Why They Should Be Used and How They Are Being Used. Theory Into Practice, 47:3, 229-239, 2008. DOI: $10.1080 / 00405840802153940$

BARDIN, Laurence. Análise de conteúdo. Lisboa: Ed 70, 2007.

BARRETO, Raquel Goular. Tecnologias nas salas de aula. In: LEITE, M.; FILÉ, W. (Org.). Subjetividades, tecnologias e escolas. Rio de Janeiro: DP\&A, 2002.

DEMPSEY, John. et al. Instructional applications of computer games. Annual Meeting of the American Educational Research Association (AERA), 1996.

FERREIRA, Andrea Francos; VASCONCELOS, Ana Karoliny da Cruz; GOMES, Cynthia Valéria Barbosa; ROCHA, Marcilma Galvão. O lúdico nos adultos: um estudo exploratório nos frequentadores do CEPE - Natal/RN. Revista Holos, 20, out. 2004.

FU, Fongling; YU, Sheng-Chin. The Games in e Learning Improve the performance. In: Information Technology Based Higher Education and Training, 2006. ITHET'06. 7th International Conference. IEEE, 2006, p. 732-738.

GEE, James Paul. Learning and games. Arizona State University: Literary Studies, 2008.

GRAMIGNA, Maria Rita. Jogos de Empresa, 2. ed. São Paulo: Pearson Education, 2007.

GRÜBEL, Joceline Mausolff; BEZ, Marta Rosecler. Jogos educativos. Revista Novas Tecnologias da Educação, v. 4, n. 2, dez. 2006.

HAINEY, Thomas et al. Students' attitudes toward playing games and using games in education: comparing Scotland and the Netherlands. Computers \& Education, v. 69, p. 474-484, 2013. DOI: https://doi.org/10.1016/j.compedu.2013.07.023 
JENKINS, Henry. Reconsidering Digital Immigrants, 2007. Disponível em: http://henryjenkins.org/2007/12/reconsidering_digital_immigran.html. Acesso em: 29 de março de 2016.

JUUL, Jesper. Half-real: videogames between real rules and fictional worlds. Massachusetts: MIT Press, 2005.

KIILI, Kristian. Digital game-based learning: Towards an experiential gaming model. The Internet and higher education, v. 8, n. 1, p. 13-24, 2005. DOI: https:// doi.org/10.1016/j.iheduc.2004.12.001

KNOWLES, Malcolm S; HOLTON, Elwood F; SWANSON, Richard A. Aprendizagem de resultados. Rio de Janeiro: Campus. 2009.

LEVY, Pierre. As tecnologias da inteligência - o futuro do pensamento na era da informática. Rio de Janeiro: Ed. 34, 1993.

LUCKESI, Cipriano Carlos. Ludicidade e atividades lúdicas, 2005. Disponível em: http://www.luckesi.com.br/ Acesso em: 3 de maio de 2015.

MARTÍN-BARBERO, Jesus. A comunicação na educação. São Paulo: Contexto, 2014.

MCGONIGAL, Jane. A realidade em jogo: por que os games nos tornam melhores e como eles podem mudar o mundo. Rio de Janeiro: Best Seller, 2012.

MINAYO. Maria Cecília de Souza. O desafio do conhecimento: pesquisa qualitativa em saúde. São Paulo: Hucitec, 2007.

MINOVIĆ, Miroslav et al. Visualisation of student learning model in serious games. Computers in Human Behavior, v. 47, p. 98-107, 2015. DOI: https://doi. org/10.1016/j.chb.2014.09.005

MORAN, José Manuel. Novas tecnologias e mediação pedagógica, 21. ed. São Paulo: Papirus: 2000, p. 59-66.

MORATORI, Patrick Barbosa. Porque utilizar jogos educativos no processo ensino aprendizagem? Trabalho de Conclusão de Disciplina. Rio de Janeiro: Universidade Federal do Rio de Janeiro, 2003.

MOUAHEB, Houda et al. The serious game: what educational benefits?. Procedia-Social and Behavioral Sciences, v. 46, p. 5.502-5.508, 2012. 
PEREIRA, Lucia Helena Pena. Bioexpressão: a caminho de uma educação lúdica para a formação de educadores, 2005, 388p. Tese (doutorado) - Programa de PósGraduação em Educação, Faculdade de Educação, Universidade Federal da Bahia, Salvador, 2005.

PRENSKY, Marc. Aprendizagem baseada em jogos digitais. São Paulo: Senac, 2012.

RABELLO, Cíntia Regina Lacerda; TAVARES, Kátia Cristina do Amaral. Tecnologias Digitais no Ensino Superior: das possibilidades e tendências à superação de barreiras e desafios. São Paulo: Blucher, 2016, p. 25-36.

RAMOS, Daniela Karine. Ciberética: a ética no espaço virtual dos jogos eletrônicos. Educação \& Realidade, v. 37, n. 1, 2012.

RAMOS, Daniela Karine. Cognoteca: uma alternativa para o exercício de habilidades cognitivas, emocionais e sociais no contexto escolar. In: Revista da FAEEBA - Educação e Contemporaneidade, Salvador, v. 23, n. 41, p. 63-75, jan./jul. 2014.

SAGA DOS CONSELHOS. Jogo Digital. Cognisense Tecnologia, Universidade Federal de Santa Catarina, 2015. Disponível em: sagadosconselhos.com. Acessado em: 10 de novembro de 2016.

SALEN, Katie; ZIMMERMAN, Eric. Regras do Jogo: Fundamentos do design de jogos, v. 4. São Paulo: Blucher, 2012.

SANTAELLA, Lucia. Comunicação ubíqua: repercussões na cultura e na educação. São Paulo: Paulus, 2013.

SANTAELLA, Lucia. O papel do lúdico na aprendizagem. Revista Teias, 13, n. 30, dez. 2012.

SAVI, Rafael; ULBRICHT, Vânia Ribas. Jogos digitais educacionais: benefícios e desafios. Novas Tecnologias da Educação, v. 6, n. 2, dez. 2008.

SCHUYTEMA, Paul. Design de games: uma abordagem prática. São Paulo: Cengage Learning, 2008. 


\section{Bruna Santana Anastácio}

E-mail: brunaanastacio@hotmail.com

Doutoranda no Programa de Pós-Graduação em Educação

Universidade Federal de Santa Catarina

\section{Daniela Karine Ramos.}

E-mail: dadaniela@gmail.com

Professora do Programa de Pós-Graduação em Educação e do Departamento de Metodologia de Ensino

Universidade Federal de Santa Catarina

Submetido em: 20-3-2018

Aceito em: 27-3-2018 